\title{
Is There a Strategic Approach of Entrepreneurship in Africa
}

\author{
Sylla Mamadou \\ Faculty of Economics and Management, University Félix Houphouët-Boigny, Abidjan-Cocody, Côte d'ivoire \\ Email address: \\ sylla87@hotmail.com

\section{To cite this article:} \\ Sylla Mamadou. Is There a Strategic Approach of Entrepreneurship in Africa. European Business \& Management. \\ Vol. 6, No. 4, 2020, pp. 67-83. doi: 10.11648/j.ebm.20200604.12
}

Received: June 7, 2020; Accepted: July 16, 2020; Published: July 28, 2020

\begin{abstract}
Entrepreneurship is a logical consequence of the transformation of our society. From the industrial era to the information age, the north and south find themselves in an almost similar situation: the need to review their socio-economic fundamentals and the need to devise new approaches in the field of work. In the near future where our grandchildren and greatgrandchildren will discover the "salary" by going to visit the museums! Indeed, our economy, based on industrialization and consumption, dates back to the early 19th century; This is infinitely small on the scale of human history. Other models existed. This is a major issue and a great responsibility for Africa. Our difficulties are twofold: the non-support of companies by banks and the immaturity of the working population. This leads to a high corporate "mortality" rate. Taxation of African countries is not a development tax. She kills them; The entrepreneurship section is made up of editors with a wide variety of interests. They share a very strong interest, even a daily obsession, for innovation in the broadest sense, companies that move and move the African continent. Their mission is to share their thoughts on the private sector, to promote inspiring entrepreneurs, social entrepreneurs, and to participate in debates on the role of companies in development. Entrepreneurship in Africa is fashionable and full of virtues. Like the term "innovation," to which it is often associated, the word "entrepreneurship" swirls in private and public managerial modes. This is why it is beneficial to step back and frame the issues and strategic approach to entrepreneurship in Africa. Everyone is an entrepreneur, some entrepreneurial successes are magnified in the big press, even in management training around the figures of transcendent and rich individuals. Entrepreneurs would be innovators, entrepreneurs' "bosses", start-ups in the new digital economy, entrepreneurship is all-round and financed in new forms. The interest of our article is to analyze entrepreneurship in Africa which is a serious matter. The overall approach to entrepreneurship is not just about starting a business, but about "entrepreneurial acting". Action is broader than action. We engage in a practitioner's approach that builds his relationship to the environment as he discovers and builds it. This is the ambition of the African entrepreneurship factory today: to act and think as an entrepreneur, in entrepreneurship.
\end{abstract}

Keywords: Approach, Strategic, Entrepreneurship, Africa

\section{Introduction}

Looking at the regularly mobilized approaches in the field of entrepreneurship, whether in thoughts or practices, it is clear convergence around a paradigm: the entrepreneurial decision. Comparing entrepreneurship in a kaleidoscope, one sees different images of entrepreneurship. These images can be summarized around the following questions: What is the contractor? Who is he? How -t structure their thoughts? How does he decide? Behind these questions shines the notion of decision. Indeed, when one asks the question "What is the contractor?", This means to question the decisions taken by it. This question refers to the economist approach (including
Cantillon and Say) Entrepreneurship, which structured and structure still approaches in the field. Ask yourself, "Who is the contractor? "This is an interest in skills, psychological and behavioral factors involved in decisions Aura to take an entrepreneur. This question refers primarily to the work initiated by psychologists to understand entrepreneurship [94]. Through the question "How -t the contractor structure his thoughts? "? this is how it thinks to make decisions. This question opened the reflection on cognitive mechanism underlying entrepreneurial" $[34,28]$. Regarding the last question, "How the contractor decides he? "It speaks for itself as it is precise in its wording of the decision. However, information that the latter question is more recent than the previous. One can understand through this question that entrepreneurship has arrived at some maturity in 
relation to the paradigm of entrepreneurial decision. Work on the effectuation [56] is emblematic of this paradigm of the decision that has structured over time approaches in the field of entrepreneurship.

If we consider that it is necessary to think otherwise entrepreneurship, however, it should not throw the baby out with the bath water. Indeed, the different approaches, whether based on thinking or practice in relation to the decision made it possible to significantly advance entrepreneurship through the paradigm of entrepreneurial decision. Our purpose is not to say that it is not good to focus on entrepreneurial decision but, more precisely, it is not good to focus exclusively on it. Specify our thinking. Merely entrepreneurial decision implicitly means that the entrepreneurial decision implicitly means that the decision is the essential element, it overrides everything, including on the action, experience or even more, on situations that the contractor is required to live. But our purpose is to emphasize that the paradigm of the decision appears as reducing the complexity of entrepreneurship and is not appropriate in some situations, even though it would be to others.

Research on entrepreneurship and culture is particularly encouraged since the 90s. Specifically, the dimensions of Hofstede's national culture (1980) linking national values and the country's economic activity. Some authors as Iribarne (1989) that it is difficult to reduce the diversity of national culture to cultural experiences of categories to describe phenomena entrepreneurial. Symbolic and emotional aspects are partially beyond the traditional explanatory models. Also, other researchers focus their work on cultural particularities affecting the personal characteristics of entrepreneurs, their motivations and their business management modes [33]. It appears very few studies addressing the entrepreneurial potential of creators in a comparative perspective. This is the meaning of about Thurik and Dejardin: "Despite numerous contributions, research on the relationship between culture and entrepreneurship is still largely in its infancy. This is especially true regarding empirical research. Its results are still treated with caution" [68]. This is especially true regarding empirical research. Its results are still treated with caution "[68]. This is especially true regarding empirical research. Its results are still treated with caution" [68].

Our research attempts to take into account such a void. It seeks to answer the question: "To what extent experienced cultural influence did they develop entrepreneurial potential of entrepreneurs?". In this sense, we postulate that entrepreneurs ${ }^{1}$ who share the same cultural experiences shape similar entrepreneurial potential. This is the case of African entrepreneurs who have previously lived in France. These cultural experiences involved in the coexistence of a double favorable socialization process for the development of entrepreneurial potential common with their French counterparts. These higher potentials than those specific to African entrepreneurs who have not had this cultural coexistence.

The theoretical perspective up such a thesis involves two

\footnotetext{
${ }^{1}$ For us, the entrepreneur is a person holding one or more companies, alone or with partners, and having at least one employee under his leadership.
}

basic approaches. The first approach focuses on the axis defined by Trompenaars and Hampden-Turner (1998) which emphasize a particularist or universalist dimension of culture. We chose to study this dimension because it provides a grid of understanding of entrepreneurial behavior Africans compared to their French counterparts. As for the second approach, it refers to personality traits, the traits of behavior and context of entrepreneurial action. These are the key features that underpin the entrepreneurial potential [32, 33]. These can be defined as the set of characteristics representing the contractor's ability to succeed in his profession.

In the end, our work sheds light on the construction of entrepreneurial potential from the phenomena of socialization. This is the case of Africans outside their country of origin. This work is part of a sociological and managerial perspective of the contractor's features. Also, the approach adopted is to double trigger. It involves first performing a summary of the main features of the work on paradigms and contractor made to better situate the entrepreneurial potential [33]. This is a reading grid that directs our fieldwork then after submitting to worship paradigm (first part). This field work focuses on the operation of three simultaneous investigations ${ }^{2}$ The first concerns a sample of 2065 French business creators, the second focuses on a group of 393 Moroccan entrepreneurs, $40 \%$ (157) lived at least five years in France and the third key Djiboutian 206 entrepreneurs, 30\% (58) were immersed in French culture for at least 5 years ${ }^{3}$. In all three cases, the information corpus used is obtained from the adapted questionnaire Gasse [32]. This is a questionnaire of 120 items out of identification factors (including history). The items are organized around 15 dimensions divided into 5-axis (motivations, skills, attitudes, interests and behaviors). Positioning the match with respect to each item is recorded on a 4-dimensional scale ${ }^{4}$. The methods of analysis of this type of data used descriptive statistics concerning techniques (flat and cross tabulations sorts) and multivariate (correlation analysis, principal component analysis and discriminant analysis). The results of these various methods of data analysis consolidate the initial thesis and open perspectives in terms of the accompanying pedagogy of African entrepreneur often subjected to cultural and contextual inertia (second part).

\subsection{Theoretical Dimensions of Entrepreneurial Potential: One Built from Approaches by the Culturally Situated Entrepreneur Traits}

Strokes and approach by facts constitute two complementary visions. The approach by the features focuses on the characteristics of the typical profile of the entrepreneur. The approach by the facts focuses on the entrepreneur as an actor before being an ideal type. The contractor is identified

\footnotetext{
2 Special thanks to our $\mathrm{PhD}$ and Master students in our second year for the completion of these investigations.

${ }^{3}$ According to the details of the United Nations (UN) for the collection of statistical data on international migration (United Nations Statistics Division, 1998), stays in a host country at least three years are more conducive the phenomenon of socialization and cultural transmission.

Most of the three surveys was conducted between January and September 2015.
} 
by its function [25] as its state of existence evolves [30]. The exercise of this function reports entrepreneurial potential. These reflect the actual capabilities and latent traits and behavioral dimensions or experience that allow the contractor to use existing resources and exploit its environment contingencies to achieve its objectives. These same traits and facts refer to cultural experiences giving the contractor a strong differential ability to risk, to the apprehension of the future, innovation and action [21]. These two theoretical axes entrepreneurial potential are briefly described in the following developments.

\subsection{Main Components of Entrepreneurial Potential}

The key success factors of the entrepreneurial process are often linked to psychological attributes of the entrepreneur. His personality and motivation are essential. The first personality trait formalized by economists and sociologists undoubtedly the most famous remains the ability to take risks. It channels the other personal traits that predispose the contractor to act in a particular way and driving entrepreneurial action successfully. This is the case of self-confidence, optimism, perseverance, autonomy or independence, fulfillment and action. The work of Gasse [32, 33] structured around the five types of components: motivation, skills, attitudes, interests and entrepreneurial behavior.

The component relative to entrepreneurial motivation relates to multiple approaches. The "push / pull" model (need / opportunity) remains the most used in research in Management Sciences [75]. Opportunity refers to the discovery of a business opportunity, while the need corresponds to a lack of alternatives (MC Mullen et al., 2008; [23]. The literature identifies several motivations for starting a business: the desire for independence, greed, the need for achievement, personality of the individual, the identification of an opportunity, looking for a lifestyle, control their own destiny, economic security for his family, building a case transmitted, etc. Most of the time, it is customary to say that human behavior is motivated by the satisfaction of three forms required; a need for achievement, a need for power and a need for independence or autonomy. These three types of needs structure the motivational dimension of entrepreneurial potential [33] and direct entrepreneurial skills.

Indeed, the skills are latent skills that have developed over the experiences and successes and to which the individual may appeal to the circumstances. These are the potential capabilities that influence learning behavior. These abilities are learned by training or experience and are used to perform tasks or job functions. Those who succeed among entrepreneurs have common characteristics such as selfconfidence, obsession with success, inexhaustible energy, a constant perseverance and an unusual stress tolerance. At such features, add some conceptual abilities such as intelligence and the ability to generalization.

This ability to generalization refers to the attitude which can be defined as a predisposition expressing values and encouraging a person to act or react in some way face a given context. Legendre [39] defines it as a "state of mind (perception, feeling, idea, belief, feeling, etc...), interior layout acquired from a person in respect of itself or any part of its environment (person, thing, condition, event, ideology, etc.) which encourages a way of being or acting for or against. "It is also "an attitude is a mental construct that expresses the values and has someone to act or react in some way deal with something. Any relationship between a person and an object of any kind implies an attitude" [2].

Perception is a filter for interest underlying passion of the entrepreneur. Indeed, passion is "a strong provision for an activity like individual, it is important and in which he invests time and energy" [70]. In this, the entrepreneur is "a passionate love freedom, who built a jail without bars" [25]. The passionate relationship of entrepreneurs to their work is the substrate of their identity. We talk about entrepreneurial passion. This is an intense emotional feeling of entrepreneurs towards business activities $[11,62]$. This feeling is associated with positive emotions like pride in the work (Bierly, Specifically, entrepreneurial behaviors are related to the orientation opportunities, taking initiative, autonomy, to change management, evaluation and acceptance of risk and its implications. They also include a set of capabilities useful in the identification, sizing and the acquisition, by all means, the resources necessary for the realization of the project. In this sense, entrepreneurship is a game of managerial behavior and individuals mobilized and skills available, oriented and shaped by identifying and pursuing opportunities. This set of behaviors and skills refer to intelligence, calculation, prudence and probity evoked by Jean-Baptiste Say.

It appears that the five components of entrepreneurial potential are from the approach traits. Some proponents of this approach even speak of psychic qualities that lead to entrepreneurial act. These include:

1. The passion for money, love adventures, inventiveness, prudence, prudence, reason, calculation, order and the economy;

2. The ability to perceive the potential opportunities, the will to act after having received the opportunity and the organizational capacity [24];

3. The tenacity and the capacity to lead a project to completion [30];

4. The breadth of knowledge related to the educational level and scale experiments [53].

These psychic qualities facilitate the transition to the measure in the light of the social context that favored their shaping. Specifically, Contractor environmental agents (friends, families, bankers, etc.) with which it interacts participate in the construction and activation of such features that structure the role of the entrepreneur [25]. This role often falls to local anchoring both the contractor is primarily a local player because it usually creates where he lives [53, 25].

But the approach of the personality traits that contributes to an image somewhat "heroic" the entrepreneur, like Schumpeter, must be qualified by the integration of motivational variables, aptitude, attitude, interests and behavior. It must also include the beliefs, values and representations that the contractor is in the middle. These are 
variables that are not without influence on entrepreneurial activities. Entrepreneurial activities are taking shape thanks to the skills mobilized. The first level of mobilization regarding the entrepreneur himself inclined to desire to excel perpetually in the workplace [94]. It is in this sense that we considers that the success related to entrepreneurship is about more than behavior traits. The approach behavior can take into account the influence of the situation and experience of the contractor. The behavioral system includes values, deep orientations that structure the representations, actions, goals and objectives of the entrepreneur. The propensity to action is a psychological variable that translates personal characteristics and motivations of the individual. They are necessary and crucial for successful entrepreneurial career. It integrates biological history, education, activity of parents, the social environment, gender, age, the power of control ("internal locus of control"), etc. [8, 36]. This predisposition led to the actual business creation under the influence of a catalyst or trigger event. But the potential entrepreneur will choose to start a business if the act of undertaking is seen as credible in view of the demands of family, social and perceived economic.

Other antecedents affecting the entrepreneurial potential. This is the case of professional experiences that can match four possible sources of exposure [39]: a concrete presence of entrepreneurs in the family, other relative or friend who has taken a job in a little past business and having started his own business. The social status of relatives also plays a role in entrepreneurial situations and career [60]. In this area, the role of relatives may take the form of role models and the preference for a career centered on the desirability and feasibility of entrepreneurial activities [63,61]. It seems that entrepreneurs most often come from families where parents or other people close themselves in business. Presumably the young, growing up in this kind of family or entourage, believes his parents or relatives as role models [76]. So, parents, brothers, spouse, family circle, friends and the associative fabric with local or national scale entrepreneurs are all key players in structuring entrepreneurial culture models [19]. considers his parents or relatives as role models [76]. So, parents, brothers, spouse, family circle, friends and the associative fabric with local or national scale entrepreneurs are all key players in structuring entrepreneurial culture models [19]. considers his parents or relatives as role models [76]. So, parents, brothers, spouse, family circle, friends and the associative fabric with local or national scale entrepreneurs are all key players in structuring entrepreneurial culture models (Doku 2011).

\subsection{Cultural Dimensions Universalistic and Particularistic Entrepreneurial Potentials Applied to French and African Entrepreneurs}

There are a multitude of definitions of culture [2, 27]. Each author gives a definition according to his research interest; Ferraro [27] have identified more than 160. One can bring them back to three trends: anthropological, philosophical and strategic [6]. The anthropological perspective sees culture as being everywhere at the same time; This is what is unique in the way we do things. The current policy regarding the system of implicit or explicit rules regulating individual and collective behavior. The philosophical approach refers to the personal development of the individual and through his theoretical and practical knowledge.

We see that everywhere and whatever the circumstances, the individual expresses his culture. Entrepreneurship can be considered then as a field influenced by culture, particularly family [9]; better, it can represent itself a cultural act. In this sense, culture relates to the profession and professional identity means in terms of expertise and psychosocial implications for agents that can act collectively [20]. In this sense, Hofstede (2001) points out that culture is inherently a collective mental programming that reflects the way of being, thinking and acting of individuals, passed from one generation to another. Collective programming is both unique and shared with with other individuals to serve as base for action.

The cultural influence model behavior Adler [2] is in this perspective conative. In this model, two types of values are highlighted: terminal values and instrumental values. The final values are related to the convictions of the individual and the goals it wants to achieve (sense of security, success, good life, family balance, self-esteem, etc.). Instrumental values relate to the beliefs of the individual and measures to be adopted to achieve the desired objectives (ambition, independence, independence, courage, etc.). Finally, the values through their impact on the attitudes and behaviors of people, is the main place to anchor and rooting of entrepreneurial culture [16].

Trompenaar and Hampden-Turner (1998) operate a good distinction between the universalist and particularist dimension component of culture. Both authors define universalism as the fact of applying the same rules and laws to all persons regardless of circumstances. Universalists crops favor the application of rules and procedures to ensure consistency and fairness in the system. Conversely particularistic cultures promote more flexibility and adaptation to local conditions and the nature of relationships that people maintain. According to these authors, African entrepreneurs, unlike their counterparts in French and Westerners in general, apply the particularist approach in business situations or solving an ethical dilemma. Indeed, Field observations show that the situational decisions are applied much more often. This is the case of corruption situations and favors of all kinds that format their formal and informal business networks.

It follows that, compared to the West, African entrepreneurs still show today more confidence to personal networks as legal contracts and are somewhat tolerant vis-àvis corruption. It is important to note also that in Africa dominates a strong cultural tendency not to trust the organizations, groups of individuals or individuals that are not part of the relational circle. The group in this type of culture is traditionally considered a block of society, which also means that Africans prefer to work more in groups than 
individually. Thereby, trust relationships are formed within the group like family, friends, colleagues. Individuals outside the group do not automatically inspire confidence. These cultural particularities refer to several realities to take into account. These include:

1. The patrimonial and clientelistic logic of certain political elites [18],

2. Red tape and barriers exacerbated by insecurity and corruption,

3. Munemo [48],

4. Economic barriers resulted in low productivity traditional agriculture dominant levels limited investment, difficult access to credit, non-existent or faulty equipment and infrastructure, etc. (Yves-André Faure taken by [41, 49],

5. Management of difficult human resources coupled with the strong presence of the informal market [29, 41],

6. The success of informal entrepreneurship because of its consistency with the local values of its adaptability to the available technology resources and socioeconomic conditions [16, 25],

7. Cohabitation of the Western way of managing the traditional way [18],

8. The coexistence three systems of thought "two imported a rational and individual (capitalist), the other rational and collective (Socialist); local, traditional family or clan" [18],

9. Social links of ethnic type that structure the cognitive dimension of entrepreneurial potential $[50,55]$,

10.Transnationalism which translates the links that immigrants maintain and develop with their compatriots (living in the country of origin in the host country, in other countries) and people of the host country $[50,10]$.

These realities are not conducive to shaping entrepreneurial potential. Yet it is essential to develop the entrepreneurial potential personal capacity in Africa, particularly from the acquisition of knowledge. This knowledge should be based on the elements of potential such as the ability to perceive and seize business opportunities, cognition, insight, taking calculated risks, persuasion and the creation of a network of contacts (professional relationship and friendship), self-confidence, etc. These potentials are involved structuring entrepreneurial skills $[17,41]$. Thus, the African entrepreneur seems to particularize byemotional motivations. These can be positively impacted by the presence of other values. This is the case of the Western entrepreneurial system, including French [24].

Indeed, the French system is essentially entrepreneurship called corporatist. According Fayolle [25], the French cultural specificities within several factors: the role of the state, the position relative to money and privilege, elitism with the selection and orientation of schools, the dirigisme, Cartesianism and fear of failure. To these are added values individualism, sense of honor, conservatism, traditionalism with real love of the craft exercised. These values are fed typologies of entrepreneurs including those of Marchesnay that combine several entrepreneurial characteristics: independence, sustainability, territorial and competitive legitimacy, notable, etc. [42]. The contractor's needs are [25]:

1. The sustainability for the family transmission.

2. Self-esteem that goes through the middle of the recognition.

3. The power that goes through professional postures (consular chamber, union bosses) or political (local political office, regional national view).

4. Corporatism mixed with consolidated autonomy through cash privileges, defense of vested interests, the preservation of economic rents, the share capital of meritocracy and academic status.

5. Individualism with a strong taste for independence.

Such needs conceal innovation and put the change in the background unlike the Anglo-Saxon entrepreneurs, including Americans. They are more focused on values such as:

1. The need for fulfillment and self-realization,

2. The competitive instinct,

3. Solidarity linked to the project,

4. Innovation and permanent modernity,

5. The dynamism and change.

Ultimately, the different cultural identities reflect the relevance of three approaches to shaping entrepreneurial potential: the approach by the aggregation of traits, that of social legitimation (or moral approval) and the approach based on dissatisfaction [67]. In the first case, it emphasizes the internalization of entrepreneurial values by individuals. In the second case, those who internalize these values and become entrepreneurs are valued. The contractor receives a high social status. The education system gives a significant place to the entrepreneurial spirit with a legislative and fiscal environment that is consistent with an incentive to take initiative. Education also plays on cultural factors "pull" or "push". The factors "pull" make entrepreneurship more attractive from the values of autonomy, independence, creativity, personal development, ability to obtain higher incomes. The "push" factors make the employment and / or unemployment less attractive and therefore the incentives for people to turn to entrepreneurship [66]. The same education system echoes the uncertainty avoidance behind the third approach [74]. The uncertainty avoidance is a cultural traits that education can manage. In fact, avoidance of uncertainty associated with individual attitudes to risk and uncertainty.

\section{Literature Review}

In our literature review, we observed that some authors believe that the African entrepreneur is often drawn between traditionalism and the mode of Western thought. So they did not comply fully with models where entrepreneurship is facilitated by the cultures where we find a greater level of individualism, a low level of uncertainty avoidance, low in degree of distance to power, a high level of masculinity [37], p34; [65]. Indeed, we will add to this collectivist aspect of their hand, will leave more leeway to employees and the ability to manage change by venturing into the unknown. 
It appears that the entrepreneurial potential acquired by those with cultural experiences in France are presented as an asset. This brings us back to the affirmation ofReynolds [53], that those who would be more likely to engage in entrepreneurship would be those that have a significant knowledge capital. this description also corresponds to a large portion of respondents that experienced cultural coexistence. Given this finding and the facts above concerning the skills to engage in entrepreneurship in Africa, we can support that cultural coexistence has provided the skills necessary but not sufficient to entrepreneurs we surveyed for success in entrepreneurship in Africa. An additional self-training seems to be necessary. That's the whole point of entrepreneurial potentials as "attitude to changes and competition."

Highlighting the common dimensions of entrepreneurial potentials shows that cultural coexistence preserves the best aspects of both cultures. Both cultural aspects seem to be combined to generate entrepreneurial potential in the African entrepreneur. We are in the presence oftransmission of entrepreneurial values allowing the African entrepreneur is to recognize [21]. In fact, African entrepreneurs seemkeep values specific to their country through other entrepreneurial dimensions such as attitude to changes, compete, design capacity and stress tolerance. These entrepreneurial structure a specific identity in line with the cultural requirements of the country of origin [12].

Basically, this double culture allows them to bring the Western view their project in Africa while retaining some African cultural standards. It is the result of several determinants of socialization. This is first level of training. The training, because of its content and quality, facilitates entrepreneurial behavior. This is especially true if the training is related to the field of activity retained by the contractor [17, 41]. This is also the case that the experience is a very important prerequisite for future entrepreneurs. This data tends to confirm that many entrepreneurs do not launch into a company without first having some experience in the relevant field. We find such in cultural experiences of African entrepreneurs surveyed. The Djiboutian shared a paid experience of the civil service with their French counterparts. As for Moroccans, their experiences in private structures, especially SMEs have certainly been instrumental in their journey entrepreneurs. The proximity to their former employers remains a significant factor. These employers seem to position themselves as true role models.

The family environment of French respondents remains a source of entrepreneurial influence. The attention of researchers focused on the parental models or marital status of the entrepreneur. It seems that the presence of a contractor in the immediate family of an individual has a positive influence. Some studies have found that $50 \%$ of entrepreneurs have a contractor relative [32]. The same observation was made by Verheul [71] and Grilo [35]. They point out that parents seem to inspire entrepreneurs and interest of their children to the status of contractor. Having a contractor parents provide a model, expertise, encouragement and practical assistance.

We are in the presence of a double social proximity that contributes to shaping the entrepreneurial potential of the entrepreneur $[16,14,36]$. Social proximity begins first by the family. Throughout history, personality traits undergo family influence to the role of contractor [9]. The role of the spouse involved in the incentive to create and throughout the creation process. This role may be particularly important if the spouse is from the contractor home country. It strengthens cultural coexistence. This same spouse can be one of the first educators of the contractor in terms of knowledge and principles of economic and social action.

In fact, entrepreneurship has a socio-cultural dimension. The family environments with a positive attitude vis-à-vis entrepreneurship constitute a breeding ground for entrepreneurship. Thus, individuals who have benefited from these cultural experiences in the business community will have more appetite for entrepreneurship. This is consistent with the analysis of Hofstede (1994) on the transmission of entrepreneurial values. These take can lead to action if the cultural context appears favorable. This is the case of Morocco and Djibouti. Note that these countries experienced significant advances in the field of entrepreneurship awareness. So, important political decisions were taken by the governments in favor of the development of the entrepreneurial culture.

Thus entrepreneurship is considered an important factor in society. The fact remains that any entrepreneurial act is preceded by intention to undertake. This plan summarizes the willingness of a person to create his own company: it can be explained by the individual characteristics of the potential entrepreneur through its environmental setting, or by its cultural specificities.

For Tournes (2006), the individual will is important in the success of the business creation process. Drucker (1970), the emergence of the entrepreneurial economy is obviously a cultural event and psychological as well as economic and technological. Lecointre (1993) argues that entrepreneurship is first and foremost a spirit, that is to say, a mentality. Business creation is simply a act that was born in a construction process.

\subsection{Context}

Figure is as follows: Place figures and tables at the top and It is undeniable today that Africa is at the heart of the world that Africa is full of immeasurable potential that makes her a subject of great envy of the world.

Experts are on same formal question that Africa is the continent of the future. But up to this level, the questions that come up and ask for eternally acute always remain those of how to go about achieving this prosperity? How to capitalize optimally and develop a strong economic fabric of social development token way?

Custom was to say in Africa, even if in demagogic outbursts is the iron spear of the nation. The demagogic studies of various countries show, it is clear that African youth is not always represented in the strategies of the future 
entrepreneurship is theirs. Frantz Fanon said then that each generation was the future that could either fulfill or betray. African youth more aware of the challenges and issues of the continent, has been observed for some years and this on the continent questioning critics refuse fatalism and the status quo. This youth is an asset that African leaders do not use it wisely.

Based in the world, the majority of women remain on the margins of development despite the Universal Declaration of Human Rights proclaims legality of rights between men and women.

In Africa, the majority of women in the workforce are selfemployed and vulnerable to shocks. Most women work for their own accounts in small-scale enterprises with low growth performance at levels poor productivity, often much less win men.

In urban areas or in urban areas, women are the backbone to own account workers, mainly in the informal sector.

In rural areas women are overrepresented among the contributing family workers in agriculture, where workers on land they do not own and the minimum economic benefits.

The average official salary employment applies to $20 \%$ women employees and decent working conditions. If available, are rarely granted to women.

Also women do two thirds of the number of working hours and produce half the food but earn only $10 \%$ of total income. They represent $70 \%$ of the 1.2 billion people living on less than $\$ 1$ a day.

Women's entrepreneurship thus appears as the main shortterm policy tool to improve the quality of female employment, contributing a structural transformation program for Africa and economic growth strategies of the states which should contribute to the well being and of families and communities, reducing poverty and empowering women.

However, women entrepreneurs still represent a minority of all entrepreneurs, especially among formal enterprises and large corporations in profitable sectors.

The labor productivity are often lower for companies owned by women in the formal and informal sector as well as in formal and informal microenterprises. Yet companies owned by women are essential to the employment of women, as they are mostly composed by women.

Given that employment suboptimal woman leads to substantial revenue losses of around $30 \%$ of GDP, the Governments of the world and various development organizations actively seek the promotion of women entrepreneurs as part of various schemes, incentives and proportional measures.

The subject is of such events that will not only broaden the knowledge we had of the strategic approach of entrepreneurship in Africa in the ethnic groups but also improve support programs, both governmental and nongovernmental to business creation. This will contribute undoubtedly create value and promote poverty reduction among women for their empowerment.

But knowledge of the strategic approach of entrepreneurship in Africa could improve the situation as necessary to understand the entrepreneurial act.

This study is timely to suggest to the government, policy makers and development partners to consider the strategic approach of entrepreneurship in Africa projects or development programs.

\subsection{Problem}

The issue of entrepreneurship in ethnic communities so stumbles on some problems: bias and even value judgments favoring some ethnic groups over others.

To not be part of the prejudices, also avoiding partisan positions taken and full of controversy, it is necessary to raise a constructive debate on the ethnic dimension of entrepreneurial intention. Ethnic groups and ethnic sentiments do exist. Since nothing seems to escape the influence of culture, the ethnic dimension appears unavoidable, the moment she reveals socio-cultural characteristics and often a parameter to be taken into account in the understanding or use of this social activity is the entrepreneurship phenomenon.

\subsection{Research Question}

The general research question concerns the strategic approach of entrepreneurship in Africa. This will be to collect the opinions and perceptions of entrepreneurs and not ethnic entrepreneurs. Specifically we want to answer the question:

"How manifests the strategic approach of entrepreneurship in Africa?"

\subsection{Main Objective}

The general objective of this study is to analyze and understand the strategic approach of entrepreneurship in Africa.

\subsection{Specific Objectives}

Specifically this study aims to:

1. Identify the reasons for the strategic approach of entrepreneurship in Africa.

2. To elucidate the values on the identification in entrepreneurship among African entrepreneurs.

3. Identify the factors favorable and unfavorable strategic approach of entrepreneurship in Africa.

\section{Research Methodology}

Recall that our research question is formulated as follows: "Is there a strategic approach to entrepreneurship in Africa?". To better understand the expected answers, we split up into three sub-questions.

1. "What are the main components of entrepreneurial potentials from African cultural particularism?"

2. "How the coexistence of African cultural values impact does it the level of entrepreneurial potential of African designers?"

3. "What is the nature of the common entrepreneurial potential that promotes such cultural coexistence?".

The first sub-question aims to bring us a new perspective on 
the features and facts of the contractor, particularly of African entrepreneurs. The final two sub-questions, they allow us to highlight the impact of cultural values in the construction of entrepreneurial potential. Indeed, they lead us to analyze the entrepreneurial potential traits of respondents designers to understand the sources of their similarity and differentiation.

Our analysis focuses on two conceptual dimensions: the transmission of cultural values and content of entrepreneurial potential. We will aim to make a comparative analysis of four groups of African entrepreneurs: two Moroccan groups and two groups Djibouti. At the four African groups, two are made up of entrepreneurs have experienced a long process of socialization in France because of studies and administrative cooperation (Djibouti cases) or because of immigration (Moroccan case). The purpose of our analysis is to identify the differentiated components of the most prominent entrepreneurial potential.

Also, we have essentially used the questionnaire Gasse, "Inventory of entrepreneurial characteristics" (ICE) and composed of 120 items out of identification factors. The questionnaire was submitted to respondents. But first, we have adapted to the French context (Northern France), Morocco and Djibouti. The final questionnaire covers 15 types of entrepreneurial characteristics in five dimensions. The first dimension addresses the motivation (26 questions). The second part focuses on the skills (29 questions) and helps identify specific qualities. The third aspect concerns the interests (12 questions) that explain the passion for innovation and the need for action in the individual. The fourth section focuses on attitudes (17 issues) evokes the perception facing certain events such as competition or change. The last dimension is related to entrepreneurial behavior (36 questions).

To express their degree of agreement or disagreement with statements regarding the different dimensions, the respondent is asked to use a scale of four categories Likert type: [A] "I totally agree," [B] "I tend to agree," [C] "I somewhat disagree" and then [D] "I totally disagree". Points are allocated according to the response: $[\mathrm{A}=4$ points $],[\mathrm{B}=3$ points $],[\mathrm{C}=2$ points $]$ and $[\mathrm{D}=1$ point $]$. Regarding the collection method, it was chosen eGovernment in the French case and face to face method in cases in Africa with a view to self-assisted administration. Regarding the profile of the respondents, it is structured by a few key characteristics [33]: age, education, work history and family.

The exploitation of the collected data was done using SPSS software. We conducted descriptive statistical analysis correlational, factorial, principal components and discriminant. Particular focus is drawn to the principal component analysis (PCA). Indeed, the ACP aims to describe the individuals in a population based on several quantitative variables. The goal is to seek new variables (major components), not correlated, summarizing the best possible information from all variables used in the analysis. These components can be described as latent variables. This is a descriptive technique of choice since it allows you to view individuals based on initial variables nearest them (Bonifas et al. 1984). Basically, the CPA allows to structure the data so that if the items measuring the same phenomenon are too far apart, several components are identified for confer the multidimensional phenomenon studied.

In this sense, the objective of the ACP is to reduce the number of initial variables while preserving the basic distribution structure. This gives a limited number of variables that provide departure information preservation [15]. The variables initially correlated are transformed into de-correlated variables. The number of variables is reduced with a less comprehensive redundant information. It is exploring the linear relations between variables and the similarities between the individuals studied (Bonifas et al., 1984). In other words, the goal is to capture as much information or variability conveyed by the data on a factorial design. This requires that the percentage of variance explained by two factorial axes is close to $100 \%$. Some other heuristics criteria exist to validate the interpretation or the selection of factor in ACP axes. But this first criterion to be close to $100 \%$ of the explained variance is most effective because it assumes that all information data is restored by the two axes.

Specifically, the number of components structuring the phenomena studied can be determined using the Kaiser indicator. We can then explain the said phenomenon from a few key variables considered. It is a decision rule used often [15]. It calls to retain components having a greater eigenvalue than 1, that is to say, the components that render more total variances. It appears that the first axis can be often identified as a reflection of the intensity variables. As such, we have used the matrix component which allows qu'entretiennent evaluate links with variable components. We respected the principle that the study of the correlation should be assumed that a coefficient of less than 0 .

\section{Presentation of Results and Discussion}

\subsection{Main Components of Entrepreneurial Potential from the French Cultural Particularism and Africa}

The results are selected mainly from the CPA. Components entrepreneurial taken into account potential have their degree of correlation between the variables and the factorial axes retained well above 0.5 . These appear as a higher extraction of quality of representation 0.5 . The measurement accuracy of sampling KaiserMeyer-Olkin is greater than 0.9 and is very close to 1. It then follows that the level of appropriateness of variables is excellent. For Bartlett's sphericity test gives a significance of 0.000 . This is a very significant result. One notes to the table total variance that the first six variables alone have over $86 \%$ of the total variance for France, $79 \%$ in Djibouti but less than $65 \%$ for Morocco. 
Table 1. The main components of the entrepreneurial potential of French creators.

\begin{tabular}{lllll}
\hline Dimensions & Score each knew dimension 4 & Own values & Variance explained & Quality of representation \\
\hline Accomplishment & 3.23 & 6.37 & $58.84 \%$ & 0.68 \\
Self-confidence & 3.14 & 1.05 & $6.13 \%$ & 0.67 \\
Cognition & 3.13 & 0.7 & $5.05 \%$ & 0.64 \\
Action & 3.16 & 0.62 & $4.15 \%$ & 0.78 \\
Autonomy & 3.26 & 0.53 & $3.9 \%$ & 0.66 \\
Innovation & 3.12 & 0.47 & $3.61 \%$ & 0.60 \\
\hline
\end{tabular}

The score of each of the six dimensions than 3 out of 4 , an average score of 3.17 or nearly $80 \%$ of ideal potential. However, only the first two dimensions (accomplishment and self-confidence) have an intrinsic value greater than 1 . This weakness is offset by the total variance explained by these six components of entrepreneurial potential. It is exactly $86.73 \%$ with a representation of quality that is around 0.70 for each of these components.

Furthermore, the statistical test of strong dependencies within the meaning of chi-square Pearson leads us to favor five entrepreneurial traits from two important clues: Statistical Significance approximate value and bilateral. These are: performance $(56.236,0.001)$, confidence $(41.163$, $0.004)$, cognition $(36.619,0.006)$, Action $(36.494,0.008)$ and autonomy $(38.745,0.001)$. The variables of accomplishment, self-confidence and action are impacted by a very low level of education (or Bac+2). By cons, those of autonomy and cognition are heavily influenced by a high level of education $(+3$ or +5$)$ and belonging to a medium entrepreneurs.

Table 2. The main components of entrepreneurial potential of Moroccan designers out cultural coexistence.

\begin{tabular}{lllll}
\hline main dimensions & Score each knew dimension 4 & Own values & Variance explained & Quality extraction \\
\hline design capacity & 2.82 & 4.82 & $30.2 \%$ & 0.72 \\
Action & 3.14 & 1.32 & $0.7 \%$ & $0.6 \%$ \\
Innovation & 2.73 & 1.21 & $6.6 \%$ & 0.69 \\
Self-confidence & 2.83 & 1.1 & $6 \%$ & 0.64 \\
attitude at competition & 2.86 & 0.96 & $5.56 \%$ \\
accomplishment & 3.15 & 0.89 & 0.62 \\
\hline
\end{tabular}

Only two components out of six scores above 3 . The average score of 2.92 , is less than $8.56 \%$ of French entrepreneurs. The entrepreneurial potential is relatively average. This makes up for the values that are greater than 1 for the first four components. For against, the explained variance is only $64.56 \%$. The quality of extraction is very honorable to nearly 0.70 .

Table 3. The main components of entrepreneurial potential of Moroccan designers cultural coexistence posture Franco-Moroccan.

\begin{tabular}{|c|c|c|c|c|}
\hline main dimensions & Score each knew dimension 4 & Own values & Variance explained & Quality extraction \\
\hline accomplishment & 3.28 & 5.55 & $34.7 \%$ & 0.715 \\
\hline Autonomy & 3.24 & 1.5 & $9.12 \%$ & 0.511 \\
\hline Attitude to change & 3.41 & 1.20 & $7.48 \%$ & 0.619 \\
\hline Action & 3.38 & 1.05 & $6.6 \%$ & 0.665 \\
\hline Self-confidence & 2.91 & 0.96 & $6 \%$ & 0.631 \\
\hline Innovation & 3.04 & 0.8 & $4.92 \%$ & 0.647 \\
\hline
\end{tabular}

Each of the six components displays a score above 3 except the variable "self-confidence" with a score of 2.91 . The average score was 3.21 , or nearly $10 \%$ higher than that of Moroccan entrepreneurs out cultural coexistence and almost identical to that of their French counterparts. This same applies to the total explained variance that goes from
$64.56 \%$ to $68.82 \%$, nearly $7 \%$ better. The most significant history relating to these characteristics include education level located "+2" and "+3 and" socio-professional category particularly affecting executives, employees / workers with a paid experience SMEs and / or contractor in France.

Table 4. The main components of entrepreneurial potential of Djibouti creators out cultural coexistence.

\begin{tabular}{lllll}
\hline main dimensions & Score each knew dimension 4 & Own values & Variance explained & Quality extraction \\
\hline Cognition & 3.18 & 6.53 & $29.7 \%$ & 0.79 \\
Innovation & 2.9 & 4.16 & $18.9 \%$ & 0.72 \\
Stress Tolerance & 2.89 & 2.32 & $10.53 \%$ & 0.68 \\
Action & 3.08 & 1.88 & $8.55 \%$ & 0.62 \\
Self-confidence & 3.13 & 1.26 & $5.74 \%$ & 0.54 \\
design capacity & 2.86 & 1.03 & $4.9 \%$ & 0.54 \\
\hline
\end{tabular}

Note that only three components of entrepreneurial potentials show a score of more than 3 to 4 . The score stands at 2.87 with the total explained variance which is at $79.1 \%$. This score is lower than that of French entrepreneurs $10.45 \%$. 
Table 5. The main components of entrepreneurial potential of Djibouti creators of cultural coexistence Franco-Djiboutian.

\begin{tabular}{|c|c|c|c|c|}
\hline main dimensions & Score each knew dimension 4 & Own values & Variance explained & Quality ofextraction \\
\hline accomplishment & 3.23 & 6.53 & $29.7 \%$ & 0.79 \\
\hline Action & 3.3 & 4.16 & $18.9 \%$ & 0.72 \\
\hline Attitude to change & 3.19 & 2.32 & $10.53 \%$ & 0.68 \\
\hline Cognition & 3.36 & 1.88 & $8.55 \%$ & 0.62 \\
\hline Innovation & 3.09 & 1.26 & $5.74 \%$ & 0.54 \\
\hline Autonomy & 3.15 & 1.03 & $4.9 \%$ & 0.54 \\
\hline
\end{tabular}

Each of the six components of entrepreneurial skills displayed a score greater than 3 on 4 . The average score is around 3.22 , or more than $12 \%$ better than the entrepreneurs out cultural coexistence and almost the same as that of the French and Moroccan entrepreneurs posture cultural coexistence. As for personal identification variables, we see that it is young entrepreneurs (under 37 years) educated $($ minimum bac +2$)$ and often employees of the function.

It appears that education, occupational category and work experience are the main antecedents that affect the level of entrepreneurial potential of African designers have taken advantage of their coexistence worship with their French counterparts. It is reasonable to consider that cultural transmission is facilitated by these three types of backgrounds. It favorably impacts the entrepreneurial potential as it results from a combination of individual and environmental characteristics. In fact, cultural transmission comes from the social, economic, political or institutional and networks established in the host territory. This same cultural transmission is likely to bring the entrepreneurial potential it shapes.

\subsection{Entre Entrepreneurial Potential from Common Cultural Franco-African Co-existence}

Reading the contents of Table 6 through signs "X" and "Y". The sign " $\mathrm{X}$ " sets the comparison between the French entrepreneurs with their Moroccan counterparts and Djiboutian out cultural coexistence. The sign "Y" does with French cultural coexistence of African entrepreneurs. Three components of entrepreneurial potential are common to the three groups of creators without cultural coexistence. These "self-confidence", "action" and "innovation." They are four in the case of postures Franco-African cultural co-existence, "achievement", "action", "autonomy" and "innovation". The Franco-Moroccan cultural coexistence and Franco-Djiboutian displays five common components, respectively "confidence" and "cognition" to complement the four initially indicated. The only component common to Moroccan creators and Djiboutian concerns "attitude towards the changes."

Table 6. Comparison the main components of entrepreneurial potential of French designers, Morocco and Djibouti.

\begin{tabular}{|c|c|c|c|c|c|}
\hline \multirow{2}{*}{$\begin{array}{l}\text { Dimensions } \\
\text { accomplishment }\end{array}$} & France & \multicolumn{2}{|c|}{ Morocco } & \multicolumn{2}{|c|}{ Djibouti } \\
\hline & $X-$ & X-- & $\mathrm{Y}$ & $\mathrm{Y}$ & \\
\hline Self-confidence & $X--\quad Y$ & X-- & $\mathrm{Y}$ & $\mathrm{X}$ & \\
\hline Cognition & $X--\quad Y$ & & & X-- & $\mathrm{Y}$ \\
\hline Action & $X-\quad Y$ & X-- & $\mathrm{Y}$ & X-- & $\mathrm{Y}$ \\
\hline Autonomy & $X--\quad Y$ & $\mathrm{Y}$ & & $\mathrm{Y}$ & \\
\hline $\begin{array}{l}\text { Innovation } \\
\text { design capacity }\end{array}$ & $X--\quad Y$ & $\begin{array}{l}X-- \\
X\end{array}$ & $\mathrm{Y}$ & $\begin{array}{l}X-- \\
X\end{array}$ & $\mathrm{Y}$ \\
\hline
\end{tabular}

\begin{tabular}{llll}
\hline Dimensions & France & Morocco & Djibouti \\
\hline Attitude to competition & & $\mathrm{X}$ & \\
Stress Tolerance & & $\mathrm{X}$ \\
Attitude to change & & $\mathrm{Y}$ & $\mathrm{Y}$ \\
\hline
\end{tabular}

In the interpretation, it seems necessary to put each component of entrepreneurial potential in a double context. The first is related to the development of the personality of each of the respondents creators and the second is the result of professional and cultural environment in which entrepreneurs operate in each country.

1. Dimensions common to entrepreneurs in three countries: achievement, action, autonomy and innovation

The accomplishment reflects "the ability to set goals, develop actions to avoid failure and to face challenges." It is a feeling of "strength" that makes you feel able to measure, "without blushing," to others and to the environment, to excel, to push the limits "almost infinite". Taken to the extreme, this search can lead to a feeling of "invulnerability" of "omnipotence" that can induce the belief that we can "do it all" and "measure to all" being sure to bringing home victory.

Although the accomplishment is the primary motivation behind the passage to the act of creation or resumption of business, this variable can appear only if the contractor has sufficient confidence to engage in the unknown. These are two very similar entrepreneurial characteristics for without need for achievement there is no risk-taking but, conversely, if there is no risk-taking if the need for achievement does s' never speak.

From a contextual point of view, the completion does not appear among African entrepreneurs out cultural coexistence. As a product of the Franco-African cultural coexistence, fulfilling a special meaning for the African creator. In fact, the degree is often more protection against unemployment. It gives more direct access to high official positions leading to significant local or national posture.

Meanwhile in France, the term of the new speech on the disappearance of patiently built career model in the company. It would change not only business but also trade several times in professional life. Meanwhile, the rapid success of young entrepreneurs, especially mediated by the Internet, suggests that success can be achieved quickly.

Microsoft, Apple, Yahoo!, eBay, Google, Facebook, Twitter... all were founded by less than thirty years. These young entrepreneurs are heroes who can dream the young people born in 1981. The new models of success via the Internet seem much more open than traditional courses in companies that are less attractive. Moreover, success is not confined to the perimeter of the enterprise: not only was 
successful, but also a celebrity is acquired. Finally, the age of the founders of some global entrepreneurial success suggests that with new technologies and the Internet, most young people have a special place.

The appetite for action reinforces the need for achievement. In fact, the action is defined as "Needs and ability of a person to react to a situation or to a result. project leader of the reaction to a configuration or in a work environment and indirectly project manager's ability to seize opportunities that may arise." The action focuses on the notion of fast results. This entrepreneurial behavior arises, again, as a "reassuring" element that reinforces the confidence in itself as described above. This variable can only appear after defining relevant objectives and therefore more easily achievable in a competitive environment.

Autonomy is a stroke of motivation often confused with independence. Recall that characterizes the autonomy need a person to decide and act only within its area of responsibility. Indeed, as long as it operates in its area of responsibility, the contractor like being "the only master on board." However, when it reached its limits, he does not hesitate to open up to the outside (working group and / or publications relating to its field of activity) to allow it to continue moving forward in full knowledge (Cognition).

Two French features were identified and may be the origin of the quest for autonomy of young entrepreneurs:

a) First, the working relationship with managers are significantly more difficult in France than in other countries, due to the persistence of strong hierarchical relationships.

b) Then, despite the importance of the value of work for the French, privacy has received growing attention among the concerns of executives, particularly because of dual careers within couples.

The need for autonomy is akin to entrepreneurial behavior of entrepreneurs who often have a strong, clear ideas about what they want to accomplish and are convincing and lead their employees and partners. So it seems logical that this dimension appears just after the previous four variables. In fact, once everything was set up for the action takes place in a relevant way, the need for autonomy becomes an entrepreneurial potential that allows the company manager to assume his bold and creative function.

It is in this sense comes in the innovative capacity of the contractor. One trait that innovation refers to having the creative mind as a project leader. This entrepreneurial behavior is probably the prerogative of creators in search of success. To win the fight on the same field as their competitors (productivity, market share, sales, etc.) they deviate slightly from the fray and choose to put their talents and imagination in the service of their vision world. Thus, they offer original ideas to improve or simply to change their supply system.

2. Franco-Moroccan and Franco-Djiboutian dimensions: self-confidence and cognition

The Self-Confidence is one of the first characteristics of entrepreneurs. Defined as "Personal development (assertiveness, speech, psychology of communication), confidence is correlated with a good Self-Esteem. It results in a positive self-representation, its achievements, its role and capabilities. It can engage without fear in relationships and in action. The entrepreneur with a good self-image is aware of its value and its potential. He is sure of himself, confident and he goes to the end of its initiatives. He knows and says make the most of their personal resources and does not suffer any side other complex. Self-confidence is a powerful engine, if not unique.

This trait allows, like the fighter jet on an aircraft carrier catapult waiting to sweep the fear related to the uncertainty of future results. It should be recalled that the fear of undertaking stems from the lack of essential points of markers to ensure that the actions will be completed. Note that this does not mean that the creator is sure to succeed or is unaware of the risks he takes. However, he is confident enough to know adapt to the difficulties he will encounter and still find a way to bounce back. This also means that if his entrepreneurial act fails, it will not consider this experience as a failure but as a learning which will enable it to start and improve its procedures. It's a learning process echoing cognition.

Only individuals who are endowed with the cognitive ability have the audacity to embark on the entrepreneurial adventure and will meet in the circuits that accompany the creators. Indeed, Cognition is defined as "the ability to make information monitoring. It can be technological, legal, financial, scientific or commercial. This is to keep abreast of information related to a field of activity for example." Cognition minimizes the risk that the creator takes when it launches in the entrepreneurial adventure. It seems logical that entrepreneurial behavior is associated with that of self-confidence. It leads to develop a comprehensive approach both technical and relational. This is behavior which led to register the new company in a context taking into account the evolution of its business scope. It is also to define the relevant objectives the need for achievement will be easier to achieve and that will strengthen the confidence in itself.

3. Dimension outcome of particularism Djibouti-

Moroccan: attitude to changes and conceptual ability

A positive attitude to changes transcribed taste for mobility and adaptation of the entrepreneur. It seems that cultural coexistence led the African entrepreneur to love doing new things or do differently with some skill to adapt. It develops new ideas, combines ideas and so create value by adapting to the context of action in his home country resources. He frees himself of part of its cultural experiences to better stimulate an entrepreneurial organization to rule out inertia in reasoning and behaviors specific to their country of origin [26].

This ability to adapt is facilitated by its design capacity, which refers to the imagination and intuition. The design capacity also reflects the personal and collective vision that underpins the objectives and suitable method to achieve this. This dimension can evoke the sensitivity level of social 
responsibility of the African entrepreneur. When an entrepreneur has to make decisions, it is often in a very complex situation, where the facts do not always decide rationally and where time imposes additional pressure (Allisson et al., 2000). In this case, the contractor must be intuitive demonstrating the ability to quickly resolve complex problems. Specifically, entrepreneurs must have a capacity for judgment including,

Moreover, each of the two cultures shows a specificity: the attitude to compete for Morocco and stress tolerance for Djibouti. The successful entrepreneur is above all a realist and assesses competition yet without being intimidated by adversity. Thus, some entrepreneurs see the competition as a business efficiency mechanism, while others tend to restrict activities to low competition niches [44, 33].

The African entrepreneur must position, especially since, already in his family, the competition among the siblings has initiated this kind of exercise. Just to live and translate in a wide range: the market. Healthy competition is a stimulant to the performance and success. For this, the contractor should consider competition as a factor of business efficiency. He should not hesitate to compete with opponents to its size. It must take a strategic combativeness and to acquire technical and managerial capacity to assess and outsmart the competition in business $[5,13]$.

In this sense, stress tolerance remains a necessary skill as it is related to the uncertainty of the economic world, the lack of benchmarks for entrepreneurial performance, management time and complexity. Stress Tolerance is an ability that characterizes the ability of individuals to bear, both physically and psychologically, abrupt environmental aggressions. The creators have often learned, sometimes the hard way, that being an entrepreneur is not a job an easy one and it requires attention, alertness at all times. Barriers of all kinds have stood in their way which, even if they have been crossed, generated a lot of stress.

If they had not been able to withstand this stress and to exceed it they would probably have been fatal both professionally and personally (eg health problems).

Fortunately for them, their ability to achieve concrete and rapid results, namely the opportunities that enable them to progress, makes their jobs easier and enables them to fulfill their responsibilities with efficiency and enthusiasm in the absence of perfect serenity. It is not uncommon also to find that these business owners are so engrossed in the operation of their business that they forget to book some time in other areas such as the family.

\subsection{Back to the Original Question: Common Entrepreneurial Potential and Differentiated Service Action}

Based on our empirical results, we will now begin the analysis of the research question. We were able to find some characteristics outlined in the literature review in the entrepreneurs we surveyed. Among these are the potentials that enable them to perceive business opportunities and to set up an organization for the action [24]. They are summarized in Table 7.

Table 7. Comparison of key-components of common entrepreneurial potential and specific.

\begin{tabular}{ll}
\hline Franco-African common dimensions & specifically African Dimensions \\
\hline accomplishment & Attitude to change \\
Self-confidence & design capacity \\
Cognition & Attitude to competition \\
Action & Stress Tolerance \\
Autonomy & \\
Innovation & \\
\hline
\end{tabular}

Through common dimensions, we see that three axes of Gasse model are mobilized. The first motivation with the fulfillment and autonomy. One of the characteristics of entrepreneurial behavior is the need of achievement, ie the need to excel and achieve a certain goal in a personal achievement goal. The need for achievement would also be pleased by the sense of progression. The contractor wants to exploit all its potential and more. To do this, he constantly seeks the challenge: he wants to compete with difficult projects he thinks he can achieve. He wants to develop his abilities and always learn more. For him, every experience is a learning opportunity. He likes to do new things or do differently. He says even learn from his failures. This positive reaction to failure is typical of entrepreneurs obstacles that arise, fear setbacks stimulate their efforts and experience of failure drives them to want to do better [33].

The search for autonomy is one of the most frequently identified factors in the motivations leading to entrepreneurship. We find as a determining factor in several works $[31,5]$. According to Katz and Gratner, the contractor would be a deviant person in that he would be unable to submit to the authority of others and adapt the structures of an organization, so it escapes Hierarchical pressure. This desire is generally found in the entrepreneur who spent several years in the service of society. He feels the need to create its own organization to make his own experiences. Operating according to the rules it has itself established, it installs its own workspace, it creates a work environment that suits him the most, and that is closest to its culture. With its years of experience, he feels a desire for independence and self.

The second axis key skills that is to say the ability of a person to perform an action. To describe analytically, it may be noted that the contractor is required to mobilize all its conceptual abilities that allow him to explain as concretely his creative project or business recovery. His skills are so widely sought to realistically describe all processes that enable the organization to create value for its customers and monetize.

The third axis is that the entrepreneurial behavior essentially represented by the variable "Innovation" and "Cognition". Innovation expresses more generally anything that refers to the imagination, originality and new ideas. As for cognition, it represents the information monitoring and the search for new knowledge. It characterizes the behavior of the entrepreneur who seeks to develop a vision as 
comprehensive as possible, the field of activity in which it positions its business.

\section{Variable of the Study}

Since the study focuses on the strategic approach of entrepreneurship in Africa, then this dimension is the independent variable, while the strategic approach of entrepreneurship in Africa becomes the dependent variable.

Other intermediate or control variables involved in the socio-cultural dimension of the strategic approach of entrepreneurship in Africa in ethnic groups such as socio demographic and socioeconomic variables.

\section{Target Population}

The study generally the socio-cultural dimension of the strategic approach of entrepreneurship in Africa in the ethnic groups. This denotes the exploratory nature of the team and that portends the creation of a non-probability sample, "Snowball", which will be obtained on the basis of a so reasoned choice of convenience.

\section{Strategy Research or Verification}

Regarding the way to deploy resources to obtain the most relevant answer to the research question as effectively as possible and to ensure the most complete verification of the hypotheses put forward, we will favor the investigation.

It is one of the most sought-after strategies in management science. In this strategy, the researcher does not control any of the variables involved.

However, based on the survey, which is a quest for information carried out by systematic questioning of subjects from a given population, it will encourage the use of the questionnaire, the survey and the interview.

\section{Information Collection}

The process for collecting information will consist of:

Step 1: Qualitative study

a) Documentary study

b) Semi directive interview

2nd step: Quantitative study

a) Love and administration

In short two data collection techniques will be retained ie the survey questionnaire and semi-structured interview. The complementarity of these two tools will help identify the strategic approach of entrepreneurship in Africa.

\section{The Data Processing}

In conducting this research, since the study is specifically within a descriptive exploratory research current and mixed referencing both qualitatively and quantitatively, in the first instance we will use the descriptive methods to determine the components of the strategic approach of entrepreneurship in
Africa and then do the analysis of independence and vary the variables analyzed are dichotomous or metric type in order to test the likelihood of advanced research hypotheses.

\section{Conclusion}

If there is common ground that the challenges facing Africa today are numerous enough, the fact remains that one on entrepreneurship and therefore economic development is of particular importance because of the weight economic power which in reality is to increase the political power, cultural or social. Indeed, one can easily realize today that states that sit on the world and impose their diktat are the most economically strong states (USA, China, Russia, etc...). Furthermore, the failure of conventional economic systems underpinned by the henceforth inability of states and private companies to absorb unemployment led national economies gradually towards an entrepreneurial type of economy.

Our research work aimed to understand the entrepreneurial potential of entrepreneurs in a comparative perspective. We started from the literature review to expose the concept of entrepreneurial potential and that of universalism / cultural particularism. This led us to develop an answer to our question from the exploitation of the field survey data. We have provided an answer to our research question through the identification of the characteristics that shape the entrepreneurial potential of respondents creators. The extraction of such features was made using the techniques of Principal Component Analysis (PCA). We have shown that some components of these potentials are identical between French and African entrepreneurs because of cultural transmission. This potential structuring skills for entrepreneurial success. We can say that African entrepreneurs who have lived in the French socialization process developed academic skills and work similar to their French counterparts.

Indeed, they are animated by a strong need for achievement that is not hampered by a lack of confidence. They were able to partially aware of their talents, their ability to lead their projects to eventually achieve their goals. They are confident in their ability to deal with potential obstacles and difficulties they might encounter.

It seems normal that we stressed the importance of need for achievement which remains the engine to support all the constraints of the business leader.

The reassuring brings achieving concrete, tangible, palpable naturally comes second because it strengthens concretely confidence that even if it developed over the years, remains no less essential. Indeed unexpected situations are numerous and the more stressful it can arise from anywhere as changes in the business world can be unexpected and sometimes profound.

Given what has been said, can be seen, naturally, the weight of innovation. This is an area in which entrepreneurs are best valued based on their excellent knowledge of the professional world and coveted market. They are aware that all original ideas can improve the functioning of their 
organizations to follow technological developments and offer more attractive offers to the customer.

Some entrepreneurs have a little more sensitivity for cognition variable that is found in strong position in the French and Djibouti. This is perhaps due to the fact that these entrepreneurs are more oriented towards the acquisition of new knowledge and to the culture of information monitoring. They appear to be essential, themselves holders of knowledge to better define the strategic direction of their businesses.

Despite the relevance and utility of these results, a qualitative analysis could complement our research. Indeed, details about the place of education and family history could shed additional light. Then a generational approach would provide additional pieces of information. This approach applied to the French case allowed us to show that Gen Y entrepreneurs (under 38) have different potentialities of their elders. The assumption that entrepreneurs of this generation, having lived in several countries from a young age, would have different potentials from those of other African entrepreneurs, deserves to be tested.

In the end, we have thus met our three sub-questions. It seems to say that permit dual cultural socialization has a decisive impact on entrepreneurship in Africa. This impact is revealed including their contribution to social capital and knowledge capital. It appears that the combination of Western and African visions provide the potential of enriching nature of the African entrepreneur. Double cropping is a solid source of entrepreneurial self-learning. Overall, the education received in the host country has favored the structuring of the main components of entrepreneurial highlighted potential. Cultural values lived on site value more highly entrepreneurial success. These cultural values are seen as the only way to Africa must therefore initiate and undertake excessive especially to make up for centuries of economic and entrepreneurial delays.

If here and there one can deplore the poor business environment (unstable environment, binding legislation, stifling taxation, political and social instability, etc...). We must also celebrate the young African pioneers, brave who decided to dare to innovate and to undertake and sometimes in areas we thought previously inaccessible to the environment. Today we can say without risk of error that Africa by its voluntary and ambitious youth has the right pulse. This past decade has seen the share of young people) to creations of innovative companies, start -up, agri-food and technology industries to the global market. While it is true, however, it must first satisfy the local market as it remains important to rake the Ages and not to set limits because the West will not make us present in this economic war that now seems more than ever to update. Indeed, research and observations of different circuits and young microcosms in Africa shows that it is not very often entrepreneurial ideas but lacking the resources (financial, material and technical) in the environment that can enable young people to materialize their entrepreneurial projects. It should therefore facilitate access to capital to avoid leakage and loss early ideas and innovative solutions. Better yet, equip young people with innovative projects, creating a suitable framework (legislative, political, economic, The study "STRATEGIC APPROACH OF ENTREPRENEURSHIP IN AFRICA" is a topic of current research for governments and communities. This study will help to understand the strategic approach of entrepreneurship in Africa.

The subject is of such events that will not only broaden the knowledge that we had the support of entrepreneurship in Africa but especially will contribute undoubtedly create value and promote poverty reduction in women for their empowerment and their participation in economic and social development of African countries.

Understanding Entrepreneurship is not easy. Many reading grids were mobilized before, namely those that have focused on the entrepreneur himself and the result of his actions. But few of them have considered how entrepreneurship is manufactured, that is to say how articulate in action the contractor, the project and its interactions with its ecosystem, that we called the entrepreneurial act.

It's time to offer a comprehensive approach to entrepreneurial. And that's what we did through this article in the strategic approach of the company in Africa. So we have shown the limitations of previous approaches to propose a new approach, that of the entrepreneurial act, based on the contractor's relationship with the world - phenomenological dimension - and objects designed by the contractor at his destination his ecosystem - size artificial sciences. However, this approach should not be considered simply as a sophistication of current approaches, but as a paradigm shift, since it is necessary to change our glasses to understand the current complexity of entrepreneurship.

The Making of entrepreneurship poses in short the question:

"What that undertaking if we accept that the contractor built entirely his own reality? "Fairly quickly, we realize that the character certainly unorthodox thoughts and approach proposed in this article, in particular compared the dominant logic based on the rational approach and Planner, can cause towards skepticism the idea that reality is constructed through the performances of the actors. Formulated this way, entrepreneurship takes a completely different meaning from the usual sense. Thus entrepreneurship would it a sense that can take entrepreneurship in Africa. The other direction that interests us through this article refers to the contractor's ability to design a project in relation to its image in the world and translate it to the actors of the ecosystem, so it can be accompanied as should it. If one accepts this sense it, this means two things. First, if so how we see the world is our own invention, we must admit that everyone does the same. Then, if we consider that entrepreneurship is composed of entrepreneurs and actors of the ecosystem, we will have to say that none of them holds the truth and that everyone should seek to join the other on his representation. This posture allows us to free ourselves from the Manichean belief that translates as follows: "Whoever is not with me is against me. "Difficulties of the contractor to adhere ecosystem 
players to its representation should be a starting point to evolve and enrich the entrepreneurial project. Thus, the Manichean belief we prefer conviction provided by this quote from Saint Exupéry: One who is different from me, far from hurting me, enriches me. " it is appropriate to gather what is scattered, as taught Vico in 1708 through the concept of ingenium, corresponding to the ability to connect things separate and opposite. In the end, it is indeed a turning point that we proposed in this article, one to remove the ruts between which African entrepreneurship is built and developed, namely entrepreneurship as objective finality, to move us toward interpersonal tolerance in a subjective perspective, the entrepreneurial act, or what counts in the adventure of entrepreneurship, it is less the destination that no contractor progressing on the path. Conviction that gives sustainability to the poem by Antonio Machado Walking is built the way.

\section{References}

[1] A tale of passion: New insights into 530 Academy of Management Review July entrepreneurship from a metaphor parenthood. Journal of Business Venturing, 20: pp 23-45.

[2] ADLER P A., (1994) Observational Techniques, Thousand Oaks, CA: Sage Publications, 1994, 145 p.

[3] Africa. Entrepreneurship in Africa: Culture, financing and development. Paris, John Libbey Eurotext, pp 7-14.

[4] ALLinSON, CW, CHELl E., Hayes, J. (2000), "Intuition and entrepreneurial," Tamara Journal for Critical Inquiry Organization, Vol. 10, Issue 1, pp. 31-39. 10.3917/rips.040.0143.

[5] ANDREWS, KR (1971), "The concept of corporate strategy", Third Edition, p 245 AURIFEILLE, J. HERNANDEZ, E. (1991) "Detection of entrepreneurial potential of students," Economies and Societies Science Series Management, pp 3955.

[6] Asheim B Boschma R Martin R Chwartz Tödtling D, F (eds.): Handbook of Regional Innovation and Growth. Cheltenham, Northampton: Edward Elgar, pp. 269-281.

[7] entrepreneurship $>>$, entrepreneurship Review, Vol 10, No. 2, p. 7-14.

[8] Asquin A. Condor R and C. Schmitt (2012) $<<$ for the mobilization of the project concept in research in Bandura A. (1989a), "A Theory of Cognitive Social Action" Recent advances in social psychology: An international perspective (pp 127-138.). North Holland: Elsevier.

[9] Bandura A. (1989c), "Perceived self-efficacy in the exercise of control over AIDS infection" In VM Mays, G. W. Albee, SF \& Schneider, The primary prevention of AIDS (Eds.): Psychological Approaches (pp 128-141.). Newbury Park, CA: Sage.

[10] BAROU, J. (2012). The sub-Saharan African immigrants in Europe: a new diaspora ?. European Journal of International Migration, 28 (1), 147-167.

[11] BAUM, JR, Locke, EA, Smith, KG (2001), "A multidimensional model of venture growth", Academy of
Management Journal, pp 292-303.

[12] Bruneau, M. (2007). The territories of identity and collective memory in the Diaspora. The geographical area, (4), pp 328333.

[13] BRUNO, AV, \& Tyebjee, TT (1982), "The environment for entrepreneurship," Encyclopedia of entrepreneurship, pp 288315.

[14] A. Carsrud, BRANNBACK M., (2011), "Entrepreneurial Motivations: What Do We Still Need to Know?", Journal of Small Business Management, Vol. 49, No. 1, pp. 9-26.

[15] CAZES P., A. CHOUAKRIA, DIDAY E., (1997), "Extension of the principal component analysis to interval-type data," Journal of Applied Statistics, Volume 45, No. 3, pp 5-24.

[16] CHABAUD D. SAMMUT S. (2014), "The behavior of entrepreneurs and buyers: the contributions of situated approaches" Journal of Entrepreneurship (Deboeck Superior), pp. pp 7-10. Chigunta, F., SCHNURR, J. JAMES-WILSON, D. and TORRES, V. (2005). Being "real" about youth entrepreneurship in eastern and southern Africa. SEED WorkingPaper, 72. pp 1-93 CLAIRE L., (2012), "Re-Storing the Entrepreneurial Ideal: Lifestyle Entrepreneurs have Hero?

[17] DEJAEGHERE, J. and BAXTER, A. (2014). Entrepreneurship education for youth in Subsaharan Africa: A capabilities approach as an alternative to neoliberalism year framework's individualizing Risks. Progress in Development Studies, 14 (1), pp 61-76.

[18] DELAYE, R. DURU, F. and Okamba, E. (2011). Cultural diversity and employability: survey on the strengths of the original culture in the process of improving the employability of students speaking African, in management science. Management \& Avenir, 43 (3), pp 180-202.

[19] DOKOU KOKOU G A. (2011), Territories and entrepreneurship: the experiences of entrepreneurial cities, Paris, L'Harmattan, 2011, pp 326.

[20] DOKOU KOKOU, GKA, (2014), Territorial Identity, local neighborhoods, and entrepreneurial capacities, Paris L'Harmattan, 2014, pp 355.

[21] DOKOU, AKG, OBRECHT, JJ, BARAY, J., PELE, M., (2016), The sustainable entrepreneurship. Generational approach in terms of entrepreneurial capabilities, Management Review, 2000, 2016/2, Volume 33, PP 181-212.

[22] Editions L'Harmattan. pp 207.

[23] EIJDENBERG, EL, \& MASUREL, E. (2013), "Entrepreneurial motivation in a Least Developed Country: push factors and pull factors Among MSEs in Uganda," Journal of Enterprising Culture, pp 19-43).

[24] ELKAN, W. (1988). Entrepreneurs and entrepreneurship in Africa. The World Bank Research Observer, 3 (2), pp 171-188.

[25] Fayolle, A. (2000), entrepreneurial dynamism and economic growth: a France-US comparison, T. VERSTRAETE, History undertaken - The realities of entrepreneurship. Managements and Societies Press, pp 297.

[26] Fayolle, A., \& DEGEORGE, JM (2012), "entrepreneurial dynamics," De Boeck, pp 275. 
[27] FERRARO FR, Dukart A., (1998), "Cognitive inhibition in Individuals prone to homophobia," Journal of Clinical Psychology, Vol 54, Issue 2, pp. 155-162.

[28] The -J Filion (2008) << entrepreneurial representations: a field of study emerging $>>$ International Journal of Psychology, vol 14, No 32 p. 13-43. Filion LJ (2017) and undertake to surround yourself human editions, Montreal.

[29] GAD, M. (2012). A better future for Africa. OECD Observer, (288), pp 70-71.

[30] GARTNER, WB (1988). 'Who is an entrepreneur?' is the wrong question. American Journal of Small Business, 12 (4), pp 11-32.

[31] GARTNER, WB (1990), "What are we talking about When We Talk about entrepreneurship?" Journal of Business Venturing, pp 15-28.

[32] GASSE, Y. (2003), "The influence of the environment in entrepreneurship," Organizations and territories, pp 49-56.

[33] GASSE, Y., LOVES, A.. (2000), "Occupation: Entrepreneur," Les Éditions Transcontinental Inc., Montreal, Charlesbourg, pp 145.

[34] Gégoire DA Cornelissen J DIMOV D \& E BURG (van) (2015), $<<$ the mind in the middle: talking stock of affect and cognition in reasearch $\gg$ Entrepreneurship, International Reviews of Management Journal, 17 (2), pp 125-142.

[35] GRILO, I. et IRIGOYEN, JM (2006), "Entrepreneurship in the US: to wish and not to be", Small Business Economics, pp 305-318.

[36] Grossetti M. BARTHE JF., (2010) "Dynamics of interpersonal networks and organizations in business start-ups," French Review of Sociology, No. 49-3, pp. 585-612.

[37] HAYTON, JC, GEORGE, G. and ZAHRA, SA (2002). National culture and entrepreneurship: A review of behavioral research. Entrepreneurship Theory and Practice, 26 (4), pp 33-52.

[38] KA Smith (1993), Nationality and work role interactions: a cultural contrast of Israeli and US entrepreneurs 'versus managers' needs, Journal of Business Venturing, 8, 6, 499-512. KATZ, J., \& Gartner, WB (1988), "Properties of emerging organizations", Academy of Management Review, pp 429-441.

[39] KRUEGER, N. (1993), "The impact of prior exposure is entrepreneurial perceptions of new venture feasibility and desirability," Entrepreneurship: Theory and Practice, pp 5-22.) Legendre, R. (1993), "Dictionary of current education," Eska, pp 150.

[40] Kshetri, N. (2007). Institutional exchange Affecting entrepreneurial in China. Journal of Developmental Entrepreneurship, 12 (04), pp 415-432.

[41] Kshetri, N. (2011). Institutional and economic foundations of entrepreneurship in Africa: An overview. Journal of Developmental Entrepreneurship, 16 (01), pp 9-35.

[42] Leadership Style: Evidence from Russia, California Management Review, Vol. 25, No. 4. Marchesnay M. (2012), Innovations, territories and international capitalism in Cardebat Uzunidi JM and D. (ed.): Territories Green, Paris, L'Harmattan, pp. 181-207.

[43] Hare P., C. Schmitt (2012), $<<$ In the heart of entrepreneurship research: business practices in SCHMITT $\gg$
C. Hare P (eds), New perspectives on entrepreneurship: practice entrepreneurial activities, Presses university of Nancy, collection action $<<>>$ Organizations, pp 13-22.

[44] LIPMAN, A. (1969), "The Colombian contractor in Bogota," University of Miami Press, pp 144.

[45] March-April 2015, pp. 103-127.

[46] McCLELLAND D. (1961), The Achieving Society, The Free Press, 1961, pp 278.

[47] MCMUlleN, JS, BAGBY, D., Palich, LE (2008), "Economic freedom and the motivation to undertake in entrepreneurial action", Entrepreneurship Theory and Practice, pp 875-895.

[48] Munemo, J. (2012). Entrepreneurship In Developing Countries: Is Africa Different? Journal of Developmental Entrepreneurship, 17 (01). pp 1-12.

[49] Naudé, W. (2010). Entrepreneurship, Developing Countries, and development economics: new approaches and insights. Small business economics, 34 (1), pp 1-12.

[50] PECOUD, A. (2005). The challenges of immigrant entrepreneurship. Journal of International Migration and Integration / Review of integration and international migration, $6(3-4)$, pp 377-403.

[51] DOORS, A. (1999). Globalization from below [The emergence of transnational communities]. Proceedings of the Social Science Research, 129 (1), pp 15-25.

[52] Psychologist, 44, pp. 1175-1184.

[53] REYNOLDS, PD (1991). Sociology and Entrepreneurship: concepts and contributions. Entrepreneurship Theory and Practice, 16 (2), pp 47-70.

[54] SAINT-JEAN E (2010), $<<$ function of mentors novice entrepreneur $>>$ Review of Entrepreneurship, Vol. 9, pp34-55.

[55] SANTELLI, E. (2010). BETWEEN HERE AND THERE: THE JOURNEY OF CONTRACTORS TRANSNATIONAL. Economic investment in Algeria descendants of Algerian immigration to France. Sociological, 1 (3), pp 393-411.

[56] Sarasvathy S. and S. Venkataraman (2011) << Entrepreneurship as method: Open issues for future year entreneurial $>>$ entrepreneurship theory and pratice, vol 35, No. 1, p. $113-135$.

[57] SCHMITT C (2012) < V VIDEO: a method to help the contractor to design a scenario from an opportunity in Filion $\mathrm{LJ}>>$ Ananou SCHMITT C and C (dir), Successful entrepreneurship without business plan Paris, Editions Eyrolles p. 99-112.

[58] SCHMITT C HUSSON J (2014) < Accompany entrepreneurial project: fresh look at coaching $\gg$ Entrepreneurship and Innovation, col 2 No. 21 P. 10-18.

[59] SCHMITT C. and Rosker E (2015) $<<$ When undertaking know is knowing conceive $>$ Review of Management Sciences, Vol. 3 No. 273 -274 p. 71-82.

[60] SCHMITT-Rodermund, E. (2004), "Pathways to successful entrepreneurship: Parenting, personality, early entrepreneurial competence, and interests", Journal of Vocational Behavior, pp 498-518. 
[61] SCOTT, MG, Twomey, DF (1985), "The long-term supply of Entrepreneurs: students' career aspirations in relation to entrepreneurship," Journal of Small Business Management, pp $1-5$.

[62] SHANE, S. Locke, EA, Collins, CJ (2003), "Entrepreneurial motivation," Human Resource Management RepView, pp 257-279.

[63] Shapero, A., SOKOL, L. (1982), "The social dimensions of entrepreneurship," Encyclopedia of entrepreneurship, pp 7290 .

[64] Smilor, RW (1997), "Entrepreneurship: Reflections on a subversive activity", Journal of Business Venturing, pp 341346 .

[65] Takyi-ASIEDU, S. (1993). Some socio-cultural factors retarding entrepreneurial activity in sub-Saharan Africa. Journal of Business Venturing, 8 (2), pp 91-98.

[66] Thurik, R. and M. DEJARDIN (2011), The impact of culture is entrepreneurial, The European Business Review, JanuaryFebruary, pp 57-59.

[67] Thurik, R. and M. DEJARDIN (2012), Entrepreneurship and Culture, in: E. Masurel and van Gelderen, eds, Entrepreneurship in Context, London: Routledge, pp 175-186.

[68] Thurik, R. DEJARDIN, M., (2012), "The impact of culture on entrepreneurship," Reflections and prospects for 2012/2 economy (Volume LI), p. 75-81 TORRES, O. (1999), SMEs; Flammarion, pp 128.

[69] University model, in Tersa V. Menzies (ed), Entrepreneurship and the Canadian universities, St Catherines, ON, Brock University, chp11, p. 71-76.
[70] Vallerand, RJ, HOULFORT, N. (2003), "Passion at work: towards a new conceptualization" Emerging Perspectives Values in Organizations, Greenwich, pp 187-204.

[71] VERHEUL I., R. Thurik, HESSELS J. VAN DER ZWAN P., (2010), "Factors Influencing the Entrepreneurial Commitment of Opportunity and Necessity entrepreneurs" SCALES, Scientific Analysis of Entrepreneurship and SMEs, pp. 57-79.

[72] VERHEUL, I., SQUARE, M., \& Thurik, R. (2009), "Allocation of time and productivity in new ventures of female and male entrepreneurs," Small Business Economics, pp 273-291. VERHEUL, I., STEL, AV, \& Thurik, R. (2006), "Explaining female and male entrepreneurship at the country level," Entrepreneurship and regional development, pp 151183.

[73] Waldinger, R. (2006). "Transnationalism" of immigrants and the presence of the past. European Journal of International Migration, 22 (2), pp 23-41.

[74] Wennekers, ARM, AR Thurik, AJ VAN STEL and Noorderhaven N. (2007), Uncertainty avoidance and the rate of business ownership across 21 OECD countries, 1976- 2004, Journal of Evolutionary Economics, 17, 2, 133-160.

[75] Williams, N., \& Williams, CC (2012), "Evaluating the sociospatial contingency of entrepreneurial motivations: A case study of English Deprived Urban Neighborhoods", Entrepreneurship \& Regional Development, pp 661-684.

[76] ZELLWEGER, T., Sieger, P., HALTER, F. (2011), "Should I stay or should I go? Career choice intentions of students with family business background, "Journal of Business Venturing, pp 521-536. 